\title{
doi.org/10.46291/ISPECIJSSHvol4iss3pp241-270
}

\section{High Vs Low: Turkish Parser's Attachment Preferences to Relative Clauses}

\section{Cengiz TURAN}

Adana Alparslan Türkeş Science and Technology University, School of Foreign Languages, 01250 Sarıçam/Adana, Turkey, email: cturan@atu.edu.tr

\begin{abstract}
The present study investigates parsing preferences to Turkish relative clauses (RC) using eye-tracker method and comprehension questions presented to the participants following each experimental sentences. In this framework, the possible effects of the RC on attachment types (low - high) were analyzed. The data gathered from a total of sixty participants were considered. Twenty-eight experimental sentences were developed based on RC and two attachment types thus, testing four conditions along with twenty-eight filler sentences. General direction of processing is that the high attachment (HA) configuration caused slightly less cognitive load than the low attachment (LA). Nevertheless, reading times belonging to HA sentences statistically longer on NP2 (the second noun phrase following the $\mathrm{RC}$ area). Longer fixation durations on main verbs were observed with significant differences in LA sentences. Regarding the answers to the comprehension questions, the data complement the findings from online processing. It can be stated that Turkish parser prioritizes syntactic operations during the early processing. However, lexical-semantic information of the main verb overrides these operations in the event of a structural ambiguity. Processing of HA sentences is more rapid than the LA sentences. Overall, Turkish is suggested to be a HA language.
\end{abstract}

\section{Key words}

Attachment preferences, relative clauses, high and low attachment, garden-path, cognitive load 


\section{Introduction}

Psycholinguistics is a field within the area of linguistics that primarily investigates psychological factors in (whether first or second) language acquisition, use, processing and production (Pickering, Clifton \& Crocker 2000). Sentence processing studies within Psycholinguistics analyze strictly controlled language properties (human or non-human host nouns, differing length and frequency of host nouns, prepositions in complex NPs, methods of disambiguation, preferentiality of hosts, number of nouns in complex NPs and so forth) through empirical methods to outline the mechanisms behind the language processing and reach conclusions about them (e.g., Traxler, Morris, and Seely, 2002; Traxler, Williams, Blozis and Morris, 2005; Just and Carpenter, 1992). Main trends in sentence processing have been to argue whether or not the human parser is universal (Abney, 1989; Crocker, 1996; Frazier, 1978, 1979, 1987; Frazier and Clifton, 1996; Frazier and Fodor, 1978; Frazier and Rayner, 1982; Philips, 1996; Weinberg, 2001) or parameterized (Bates and MacWhinney, 1982, 1987; Gibson et al., 1996; Gibson et al., 1999; Hemforth et al., 1998; MacWhinney, 1987, 1997; MacWhinney and Bates, 1989; Mazuka and Lust, 1990) and whether attachment preferences and methods of disambiguation are frequency-based or language-specific (MacDonald, 1993, 1994, 1997; MacDonald et al., 1994; Spivey-Knowlton et al., 1993; Spivey-Knowlton and Tanenhaus, 1995; Taraban and McClelland, 1990; Thornton et al., 1998; Thornton et al., 1999; Trueswell and Tanenhaus, 1994; Trueswell et al., 1993).

The research on relative clauses (RC) within the field of psycholinguistics is quite prolific. The RCs have been investigated regarding first and second language acquisition, language processing comprehension and production. The processing of the RCs focusing on English and other typologically-similar languages (head-initial languages) has been a topic of investigation in numerous studies (e.g., Caplan et al., 2001; Gibson, Hickok, and Schutze, 1994; Gordon, Hendrick, and Johnson, 2001; King and Just, 1991; King and Kutas, 1995; Pickering, 1994; Traxler, Morris, and Seely, 2012; Weckerly and Kutas, 1999). On the other hand, the studies on head-final languages, including Turkish, are needed to test the widely accepted generalizations and create a framework for language processing specifically for these languages (Papadopoulou, 2006). Moreover, the studies on the RC attachment preferences in Turkish are scarce (Kırkıcı, 2004; Kaya, 2010 and Dinçtopal-Deniz, N., 2010; Başer, 2018). These studies analyzed certain linguistics structures of genitive possessive 
constructions ([NP1 $\left.1_{\mathrm{GEN}}+\mathrm{NP} 2\right]$ and prepositional phrases $\left.\left[[\mathrm{NP} 1 \mathrm{P}]_{\mathrm{PP}}+\mathrm{NP} 2\right]\right)$ that were previously studied in other languages. However, possessive compounds [NP1+NP2 2 OSs $]$ and $\left[\mathrm{NP} 1+\mathrm{NP} 2_{\mathrm{ACC}}\right]$ compounds in the RC attachment have not been studied so far. In addition, whether Turkish primarily prioritizes high or low attachment to RCs has not been established. All these points make it clear that the RC attachment preferences should be analyzed in Turkish, and Turkish language should be described based on these features.

The present study aims to investigate Turkish native speakers' attachment preferences to RCs. Within this broad scope, considering online reading times and offline comprehension question-answer pairs, it is aimed at describing the processing differences between high and low attachment to RCs.

Turkish RCs have generally been considered in the context of gapping and movement (Kornfilt, 1997: 57). They are accepted to be complex nominal structures that modify noun phrases and thus functioning similar to adjectives. As in the case of adjectives, Turkish, which is a head-final language, also allows the RCs to the right of the noun they modify (Underhill, 1974). Kornfilt (2000) states that predicates are observed at the end of clauses and inflectional suffixes follow the predicate.

Kornfilt (1997) argues that Turkish RCs are nominalized structures, which means that they are non-finite. Overt relativizers such as who, which, and that employed for English RCs are not used in Turkish RCs. Instead, RC participles suffixed to the RC verb serve the functions carried out by these relativizers. -(y)An and -DIK are the two mainly employed RC suffixes used in Turkish. Underhill (1974) stated that -(y)An type is used when the head noun is the subject of the underlying sentence and -DIK type is used when the head noun is not subject. Thus, verbs are inflected with -(y)An and -DIK to form subject and object RCs, respectively (Kornfilt, 2009).

Research on RCs in psycholinguistics has produced a considerable number of models and hypotheses that attempt to explain what stages the parser goes through and how it processes sentences. It is postulated that human parser may be serial or parallel, modular or interactive. Regarding the method of processing, it could be universal, parameterized or dependent solely on frequency of the experienced incoming linguistic structures (Papadopoulou, 2006).

In the event of a potential ambiguity, in which the parser is supposed to make a decision between two conflicting interpretation, the first purely syntactic analysis is completed through Year 4/ 2020, Volume-4, Issue-3 | WWW.ispecjournal.org 
two models: Late Closure and Minimal Attachment (Frazier, 1987; Frazier and Fodor, 1978). It is required by Late Closure that the emerging linguistic elements be attached to the phrase that is being parsed. The Minimal Attachment commands that the incoming material be processed so that the least number of nodes are created also assuring the well-formedness of the utterance. These two principles are thought to explain the speed and efficiency of the parser in processing the linguistic input. It is claimed that the nature of the parser is identical across all human languages and the principles are thus universal. Possible differences in parsing are only attributed to unique grammatical properties of individual languages.

Various studies have contributed to the predictions and principles that the Late Closure holds so far with numerous studies (Ferreira and Henderson, 1991; Frazier and Rayner, 1982; Kennedy and Murray, 1984; Mitchell, 1987).

The Late Closure and Minimal Attachment were challenged by the seminal study of Cuetos and Mitchell (1998). They dealt with the RC attachment preferences of English and Spanish speakers. The first NP the servant, in sentence (1) is accepted as high because in the syntactic tree it is positioned further away from the RC. On the other hand, the NP the actress is termed as low due to its closer position to the RC. As for the Late Closure, the RC is to be attached low to the constituent the actress.

(1) Someone shot the servant of the actress who was on the balcony.

(Papadopoulou, 2006: 12)

Kırkıc1 (2004) is one of the few researchers that investigated the RC attachment ambiguities. In his offline experiment, the sentences were manipulated so that complex noun phrases marked with genitive case ([NP1 $\left.\left.1_{\mathrm{GEN}}+\mathrm{NP} 2\right]\right)$ could be attached to the RCs site, which causes the ambiguity. The result of the experiment shows that participants were observed to attach RCs to low NPs. Furthermore, it is stated that lexical-semantic information and animacy information of the potential NPs establish conclusive arguments for NP choice to be attached to RCs.

Dinctopal-Deniz (2010) also studied sentences with ambiguous RCs. The aim of the study was to observe how attachment ambiguities were handled in sentences with RCs. Ambiguities used in the online study were of two kinds as temporal and global. For the disambiguation of temporal ambiguities, animacy information on NPs included in complex genitive NPs was 
provided. Global ambiguities were planted in sentences of the offline task. Three groups of participants (Turkish monolinguals, Turkish learners of English at high levels and English monolinguals) participated in the study. The data from the participants were gathered through online self-paced reading tasks and offline questionnaire answering. Overall, results of the experiment suggest that Turkish and English monolinguals preferred low attachment to the RCs in both tasks. Turkish learners of English exhibited low attachment preference in the online task although it was not statistically more significant than high attachment.

Kahraman (2015) investigated the SRC/ORC asymmetry in context. It is stated that the ORCs are mostly context-bound structures and the reason for difficulty in processing of the ORCs as observed in previous studies can be cleared if they are accompanied by context. Inspired by the Discourse Context Function Hypothesis (DCFH) (Roland et al., 2012) he paired his experimental sentences with two types of contexts as seen below:

Neutral context:

(2) Üniversite yolsuzluk yüzünden inceleme-ye al-1n-d1.

University corruption due to investigation-DAT taken-PAST.

The university was investigated due to corruption.

SRCs:

(3) [Dekan-1 suçla-yan] rektör okul-u düşün-üyor-du.

[Dean-ACC blame-SPART] rector school-ACC think-PROG-PAST

The rector who blamed the dean was thinking of the school. ORCs:

(4) [Dekan-1n suçla-dığ-1] rektör $\quad$ okul-u düşün-üyor-du.

[Dean-GEN blame-NSPART-3 ${ }^{\text {rd }} \mathrm{SG}$ ] rector-NOM school-ACC think-PROG-PAST-3 ${ }^{\text {rd }}$ SG

The rector who the dean blamed was thinking of the school.

Topic context:

(5) Dekan fakülte-deki işleri-ne fazla önem ver-mez-di.

Dean faculty-LOC work-DAT much care give-NEG-PAST- $3^{\text {rd }} \mathrm{SG}$

The dean did not care much about his work at the faculty. SRCs: 
(6) [O-nu suçla-yan] rektör okul-u düşün-üyor-du.

[He-ACC blame-SR] rector school-ACC think- PROG-PAST

The rector who blamed him was thinking of the school.

ORCs:

(7) [O-nun suçla-diğ-1]

rektör okul-u düşün-üyor-du.

[He-GEN blame- NSR-3SG] rector school- ACC think- PROG-PAST

The rector that he blamed was thinking of the school.

(Kahraman, 2015:101)

The NPs used in neutral context do not appear in RC. On the other hand, the NP used in RC is the topic NP in topic context. Before the implementation of their self-paced reading experiment, it was claimed that if processing difficulty with ORC sentences had been due to a lack of context, such asymmetry would have been eliminated with the inclusion of context. True/False comprehension questions were also added to the analysis of the experiment for observing comprehension accuracy. Their conclusion on SRC/ORC asymmetry is that the processing difficulty of ORCs did not differ compared to the SRCs even when provided with a context. Their results do not comply with the DCFH by (Roland et al., 2012).

The acquisition of English RCs by Turkish native speakers was investigated by Turan (2012). His study indicated that accessibility of the Universal Grammar (UG) is a defining factor in the acquisition of English RC in lower levels (Pre-intermediate or A2). However, in higher levels, access to UG is limited and transfers from Turkish as a native language is administered more. Thus, it was concluded that in the acquisition of English RCs by Turkish native speakers, Full Transfer/Partial Access (White, 2003) defines the acquisition of this construction.

In her PhD dissertation, Başer (2018) studied syntactic priming effect of attachment on RCs in monolingual Turkish speakers and Turkish learners of English with various proficiency levels. The aim of the study was to compare the strategies practiced for ambiguity resolution in Turkish and English. The data collection was carried out by an offline (written questionnaire) test, an online (self-paced reading) test and an eye-tracking test. The findings of the study reveal several constraints on the RC attachment preferences. Whether the host NP is animate or not, semantic relations between the host NPs, the semantic association of the host NPs with proximal and the distal predicate and active/passive RC condition are the 
factors that influence both groups in their processing strategies to RC attachment preferences and ambiguity resolution. It is also stated that high attachment preference is associated with processing difficulty.

\section{Method}

\subsection{Pilot Studies}

Two pilot studies were implemented prior to the full-scale implementation. Certain alterations and improvements were brought to the research design. It was determined for participants' linguistic background and exposure to a second language to be controlled. An equal number of target and filler sentences were suggested and accepted. It was also revealed that sentence lengths and complexities were not standard throughout the sentence list, thus causing uncontrolled reading times and deviation from the focus of the study. Number of items on per sentence and their structural complexities were standardized in order to form a unity.

\subsection{Participants}

The number of participants in the study was sixty-eight native Turkish speakers. All of them were undergraduate students in their first year at a state university in Adana, Turkey. The participants were chosen among volunteer students of the researcher and some extra points were also granted for their participation at the end of the semester. Considering the results of the gaze sampling data, six participants were excluded from the study as their gaze samplings were below $80 \%$, which was considered as a baseline. Besides, two participants' data were not considered in the experiment as their grades from the comprehension questions were lower than $75 \%$ which contradicts with the second criteria in which the participants' comprehension question grades were required to be $75 \%$ or over. Therefore, the final number of participants was sixty (Female: 32, Male: 28). All of them were monolingual, native Turkish speakers, and they had never been abroad and exposed to another language until critical age. All of the participants had normal or corrected to normal vision.

\subsection{Materials}

The total number of sentences in the study is fifty-six. Out of these sentences, the target sentence set, which included twenty-eight sentences, was divided into two groups as SRCs (fourteen) and ORCs (fourteen). Under each group attachment preferences, HA (seven), and Year 4/ 2020, Volume-4, Issue-3 | WWW.ispecjournal.org 
LA (seven) groups were manipulated. Thus, in the study four conditions were tested. These conditions included two RC types and two attachment types, which are shown below:

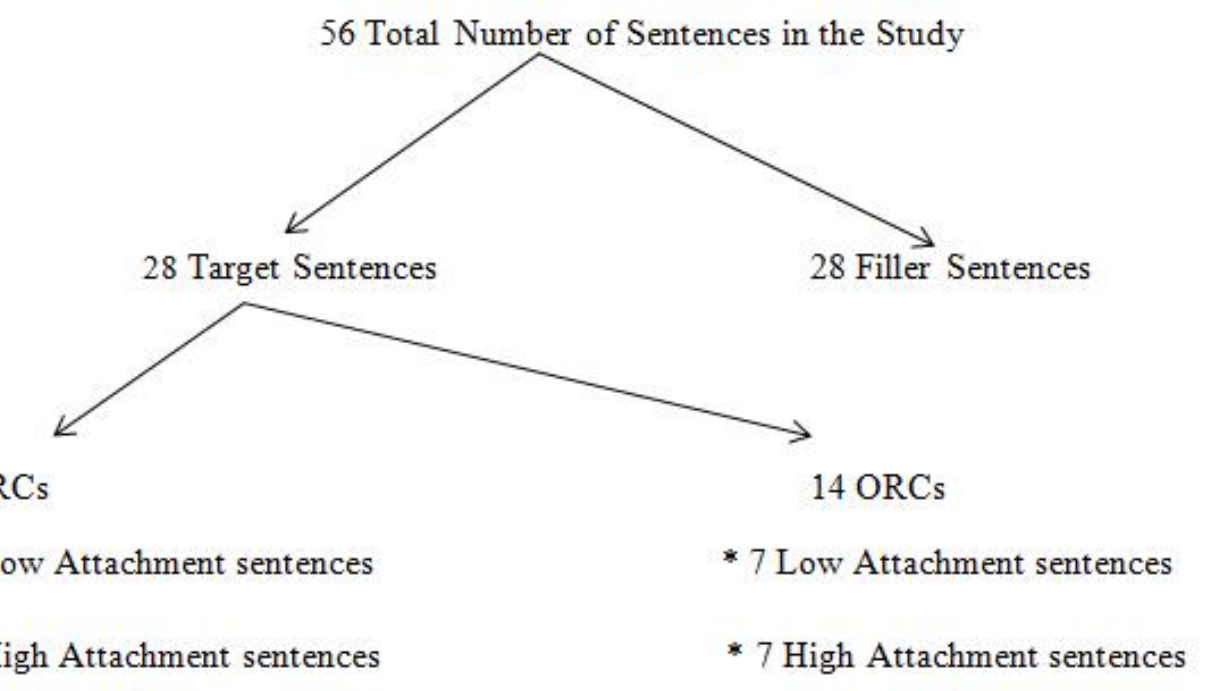

* 7 High Attachment sentences

Figure 1. Design of Experimental

Sentences

The rationale for the total number of twenty-eight experimental sentences in the study is due to maintaining an optimum working memory load of participants. Completion of each experiment by the participants lasted approximately 9 to 11 minutes. A longer duration is supposed to impair their performance on reading the given sentences and their answers to comprehension questions. An even number of experimental items is the key to collecting accurate data; therefore, in essence seven items of each manipulation were determined. The sum of all items amounts to twenty-eight and combined with the other half of filler sentences, the total number of the items is fifty-six, which are also accompanied by comprehension questions.

The sentences below are the examples of target sentences containing RCs and distinct attachment patterns. 
(8) SRC/LA

[Zabıta-y1 gör-en] bakkal çırağ-1 hemen içeri girdi.

SRC LOW

[Police-ACC see-PART] grocery assistant-POSS immediately inside enter-PAST-3 ${ }^{\text {rd }}$ SG.

SRC LOW

The grocery (owner) assistant who saw the police went inside immediately.

(9) SRC/HA

[Zabita-y1 gören] bakkal telefon-u hemen elin-e

SRC

[Police-ACC see-PART] grocery owner telephone-ACC immediately hand-POSS-DAT

SRC HIGH

ald1.

take-PAST-3 $3^{\text {rd }}$ SG.

The grocery owner who saw the police took the telephone in his hand immediately.

(10) ORC/LA

[Şehr-in sevdiğ-i] takım kaptan-1 çabucak ilgi-ye alıştı.

ORC Low

[The city-GEN love-PART-POSS] team captain-POSS quickly interest-DAT adapt-PAST$3^{\text {rd }} \mathrm{SG}$. LOW

ORC

The team captain whom the city loves quickly adapted to attention.

(11) ORC/HA

[Şehr-in sevdiğ-i] takım baklava-yı çabucak eller-i-ne

ORC HIGH

[The city-GEN love-PART-POSS] team baklava-ACC quickly hand-POSS-PL-DAT ORC HIGH

ald1.

hold-PAST- $3^{\text {rd }}$ SG.

The team which the city loves quickly held the baklava in their hands. 
The term 'high' or 'low' is attributed to the distance of the NP to the RC. The NP that is closer to the RC is termed as low and the second NP following the RC is high. Central to the discussion of NP attachment to RCs in Turkish, Öztürk and Erguvanl1 (2015) state that three structures can be used for possession relation: genitive possessive construction (GP), possessive-free genitive construction (PFG) and the genitive-free construction, also known as the possessive compound (PC).

(12) Kadın-ın

woman-GEN doktor-u doctor-3PS-POSS
(GP)

(PFG)

$$
\text { doktor }
$$

woman-GEN doctor

The doctor of the woman

(14) Kadın

doktor-u

(PC)
doctor-3PS-POSS

Women's doctor (gynecologist)

(Öztürk and Erguvanlı, 2015:623)

In the present study, PCs that are given in (14) are employed to investigate attachment preferences of Turkish speakers to RCs. Öztürk and Erguvanlı (2015) indicate that PC structures along with PFGs (13) imply the presence of a PP. Unlike the GP (12), the possession relation in PC and PFG does not include temporal value. Thus, it is parallel to an individual-level interpretation. It is argued that the relation between two nominals in possessive phrases resembles to the relations established by prepositions.

As seen in the target sentences above, the main verbs which are used also differ according to their argument structure. In the LA sentences, the main verbs are transitive and take only one argument.

[DP__ $]$ V- gir- (to enter), - alış- (adopt)

In the HA, the main verbs are all ditransitive and take two arguments.

$[\mathrm{DP}$ DP $\{$ DP/PP $\}]$ V - gönder- (send), - al- (hold) 
The experimental sentences given above were employed in an online experiment using an eye tracker to collect the data on reading time of the participants. The comprehension questions were asked the participants following each sentence in the study. An example True-False sentence following a target sentence is presented below.

\section{Doğru/Yanlış?}

Bakkal çırağı hemen içeri girdi.

Figure 2. Sample Comprehension Question Item

An additional groups of twenty-eight filler sentences were used to distract participants from the purpose of the experiment. While designing the filler sentences, subordinate sentence structures including RCs in Turkish were chosen in order to achieve a balance between sentences in terms of structural complexity. Below are some examples of the filler sentences that were used in the experiment.

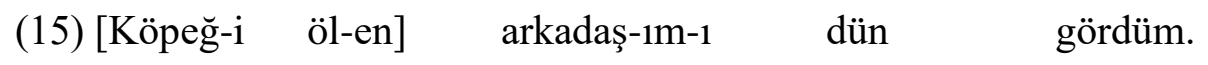

[Dog-POSS die-PART] friend-POSS-ACC yesterday see-PAST-1st SG.

Yesterday, I saw my friend whose dog died.

(16) [P1rasa-dan nefret ed-en-ler] çoğunluk-ta-dır.

[Leek-ABL hatred practice-PART-PL] majority-DAT-be-3rd SG

(The ones) who hate leek are the majority.

$$
\text { [150. kez soy-ul-an] ev sonunda y1k-1l-d1. }
$$

$\left[150^{\text {th }}\right.$ time rob-PASS-PART $]$ house finally demolish-PASS-PAST-3rd SG

The house that was robbed for the 150th time has finally been demolished 


\subsection{Data Collection Tool}

The data from the experiment were were via a Tobii Technology 1750 eye-tracker with a 17" TFT monitor (1280x1024 pixels) integrated to it. The device collects eye-movements and fixations at a rate of $120 \mathrm{~Hz}$. The device was rented from a supplier in Ankara and shipped to the researcher's office. The data collection was carried out between 11 November 2016 and 14 November 2016. The participants read the sentences displayed on a computer screen while the integrated eye tracking system recorded where and how long the participants' eyes fixated. As a second measure, the comprehension questions appeared on the screen after each sentence, which provided a comparison with the eye-tracking data.

\subsection{Procedure}

Before the experiment started, some questions were asked to gather information about the participant profiles such as "Is Turkish your native language?", "Do you speak another language?", "How old are you?", "Have you lived abroad and if yes, how long?" Participants were chosen from students who did not wear glasses. Female participants were asked not to wear make-up as it could deteriorate the eye-tacker camera results due to reflecting lights. Then, each participant was instructed about how to navigate through the sentences during the experiment. Then, their eye pupils were calibrated with the device. Distance to the monitor and sensors below it are crucial to collecting accurate data. Therefore, each participant was made to sit in front of the monitor within $60-70 \mathrm{~cm}$. In order to stop participants fixating their gazes at the very beginning of sentences so that they could start reading the sentences however they prefer, a star was placed on a random place on each slide and participants were asked to look at it before they start reading the sentences.

Prior to the beginning of the experiment, each participant was given instructions by the researcher. It was announced that they were supposed to press space button on the keyboard after they silently read the given sentence and fully comprehend it. Participants were allowed to press "TRUE" or "FALSE" button after reading the comprehension questions for each of the given sentences. Having pressed either button, the participants repeat the cycle with the star on the next slide. In order to prevent "order effect" (Schuman and Presser, 1981), two sets of stimulants were presented to participants to read and answer. The first set follows a certain order of experimental (target) sentences jumbled with the filler sentences. The other involves the opposite order so that possible lower reading times for the initial items and higher reading Year 4/ 2020, Volume-4, Issue-3 | WWW.ispecjournal.org 
times for the last items would be eliminated. The participants with even numbers were given data set 1 sentence list while participants with odd numbers were given data set 2 .

Tobii eye-tracking device software allowed jpeg formatted pictures for the experiment. Thus, the sentences were first written on MS Word and then transferred into MS PowerPoint. The transformed sentence list was later saved as a separate file, in which each of the slides were converted into individual jpeg formatted pictures, which were finally compatible with the software of the eye-tracker. Calibri font and 26 character size were used for the experimental sentences. The sentences were black in color while the background was white.

In order to collect reading times of participants from the given sentences in the study, the device recorded each participant's reading times for critical parts of the target sentences, which are called "area of interest" (AoI), as the participants read the sentences. The software of the device calculates how long each participant spends reading a certain AoI and also, provides a number of descriptive statistics such as Mean, Median, Standard Deviation and others. Reading times (Sum) were collected from the software of the eye tracker program.

An example illustration of AoI collected from the eye-tracker is given below.

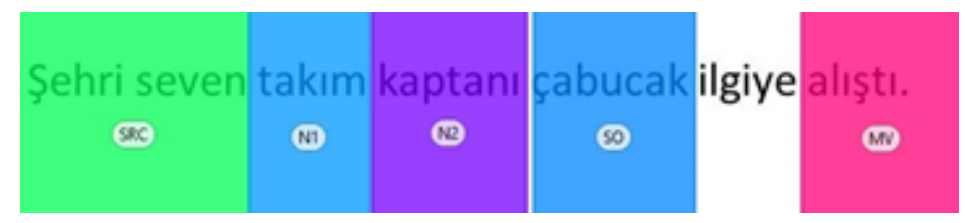

Figure 3. An Example AoI

The first AoI is SRC or ORC, which also determines the type of the sentence. N1 refers to the noun phrase that immediately follows the RC area. $\mathrm{N} 2$ is the second noun phrase that follows the RC area. These are key to analyzing attachment preferences to RC area. SO area is a location that observes whether the participants perform a spillover effect in which reading times carried from N2 could be traced. MV is the main verb area. Reading times from this area depending on sentence types yield crucial data to discuss on processing of given sentences. All AoIs are handled individually and factors that influence reading times are discussed across the sentence types.

\subsection{Data Analysis}

The reading time data and answers to the comprehension questions gathered from the eyetracking device are analyzed in order to describe the attachment preferences and the RC 
asymmetry in Turkish in the present study. For the comprehension questions, the independent variables are the attachment types (LA, HA) and the RC types (SRC, ORC) and the dependent variable is correct answers to the question. Considering the reading times collected from the eye-tracking device, the independent variables are again the attachment types and the RC types while the dependent variable is reading times. For reading time analysis, two reading time measures (first fixation duration and total fixation duration) are used.

Initially, from a statistical point of view, participants' reading times and the answers to comprehension questions are analyzed to find out whether they display normal distribution or not. If the data in a study have a normal distribution, it means that differences in participants' responses are within acceptable ranges. It also suggests that the study has a relatively more homogenous population. Normal distribution, according to Tabachnick and Fidell (2013), is accepted to be between $+1,5$ and $-1,5$ while George and Mallery (2010) state that it is between $+2,0$ and $-2,0$.

Whether there is normal distribution or not also determines tests to be used in the data analysis. If the normal distribution of the data is observed, the parametric tests are used. However, if there is no normal distribution, the non-parametric tests are to be employed. In the study, as normal distribution is observed, the parametric tests are utilized. Büyüköztürk (2007) indicates that in studies with more than 50 participants, the Kolmogorow Smirnow test is administered and if the number is below 50, the Shapiro-Wilkis test is used. It is also stated that the significance value of more than 0,05 implies a significant normal distribution. As the present study includes 60 participants, the Kolmogorow Smirnow test is employed. Eymen (2007) suggests that t-tests are used on two related but different data sets of a certain group. Büyüköztürk (2007) states that three conditions are required for t-tests to be used. The first is that the data must be within interval scales, the second is that the data must show a normal distribution and the third is that variance homogeneity must be maintained. Therefore, in the analysis of both reading times and comprehension questions, the independent $\mathrm{t}$-test is used for two-way comparisons. 


\section{Findings and Discussion}

\subsection{Analysis of Attachment Preferences to Relative Clauses}

The specific AoI (RC, NP1, NP2, SO and MV) reading times are analyzed in a two-way comparison among the LA and HA sentences in terms of first fixation duration (FF) and total fixation duration (TF) reading times. The aim was to reveal which attachment type is processed in longer or shorter time. A comparison of reading times on specific AoI reveal data to discuss on. Furthermore, the factors and strategies affecting the processing were further scrutinized.

As stated before, the data had a normal distribution. Therefore, T-test was employed to seek whether the attachment types are significantly different from each other regarding the AoIs.

In Table below, the descriptive statistics for two target sentence types are listed. The participants encounter RC areas as they incrementally read the target sentences. For this reason, the analysis of findings starts with presenting FF reading times for this AoI.

Table 1. Descriptive Statistics on Attachment Types for AoI 1 (RC) in FF Duration

Type of Attachment

Low Attachment

High Attachment

\section{Mean}

, 1346

, 1447

\section{Std. Deviation}

, 02255

,01895
$\mathbf{N}$

60

60

In Table 1 above, the descriptive statistics about AoI 1 ' $R C$ ' collected from all attachment types considering the first fixation duration reading times are presented. Considering the mean values, the reading times for the LA sentences $(X=, 1346)$ have the lowest while reading times for the aforementioned AoI is the highest for the HA sentences $(X=, 1447)$.

In order to see whether the differences have a statistical significance, T-test test is employed. A statistical difference between LA and HA sentences was not observed concerning FF duration reading times for AoI 1 (RC area).

The findings suggest that the insignificance in the reading times yields significant results for the sake of the study as it only increases the reliability of the implementation. The participants, in the FF duration, process the same incoming data including the same RC and NP. Similar as well as insignificant reading times suggest that the participants face the same 
cognitive load during early processing. Also, the fact that the two data sets (one with the opposite order of the other) were used also balances the order effect (Schuman and Presser, 1981), and presents more equally distributed reading times.

For the second part of the analysis of AoI 1, the total processing durations are considered. In this part, all the regressive fixations including the first fixations are combined and the figures in Table 2 are presented. Depending on the difficulty of processing of each sentence types, the reading times present diverging reading times as seen in Table 2 below.

Table 2. Descriptive Statistics on Attachment Types for AoI 1(RC) in TF Duration

\begin{tabular}{llll}
\hline Type of Attachment & Mean & Std. Deviation & N \\
Low Attachment & 1,1367 &, 39232 & 60 \\
High Attachment &, 9601 &, 39299 & 60 \\
\hline
\end{tabular}

Table 2 presents that when means of the sentence types are concerned, higher reading times were observed on the LA type $(X=1,1367)$. Shorter reading times belong to the HA sentence type $(\mathrm{X}=, 9601)$ as seen in Table 2 above.

In order to see whether the differences in these mean values have a statistical significance, Ttest was administered. Considering the test results for the sentence types, Table 2 above shows that significant differences $(\mathrm{p}=, 001)$ are observed between the Low and High Attachment sentences. More specifically, significantly more amount of time is spent for the Low Attachment sentences. The cognitive load for parsing the $\mathrm{RC}$ area for the High Attachment sentences seems to be lower. A clear difference between FF and TF durations was observed in terms of LA and HA sentences. Although the LA sentences had shorter reading times for AoI 1 in FF duration, the HA sentences were observed to be read in shorter time in TF duration. The total processing time which was spent to successfully attach the RC area to only one NP in the HA sentences is completed with significantly less cognitive load than in the LA sentences. It could be stated that the LA analysis causes heavier burden for the parser. It is discussed later in the further AoI analyses; however, it could be briefly stated here that although leaving the node for NP1 open for further incoming words can be thought as an economical nature of the parser, it causes conflicting situation. Late Closure (Frazier and Fodor, 1978) is the case in the La sentences. During the parsing of the RC area, a high level of animacy-sensitiveness enables the reader to include NP2 in the opened node and to attach it to 
the argument of the RC area. Finally, it is safe to state that significantly shorter reading times are the case for the HA sentence type in terms of the RC area.

AoI 2 which is abbreviated as 'NP1' is analyzed through the sentence types in terms of FF reading times. NP1 is the very first noun that immediately follows the RC area. This AoI is once again the same word across all attachment types.

The descriptive statistics for two target sentence groups are presented in Table 3.

Table 3. Descriptive Statistics on Attachment Types for AoI 2 (NP1) in First Fixation Duration

\begin{tabular}{lccc}
\hline Type of Attachment & Mean & Std. Deviation & N \\
Low Attachment &, 1748 &, 03405 & 60 \\
High Attachment &, 1649 &, 02831 & 60 \\
\hline
\end{tabular}

Table 3 indicates that the reading times for the LA sentence type $(X=, 1748)$ have higher mean values than HA sentences $(X=, 1649)$.

In order to see whether the differences in reading times have significance, T-test was administered. Significant differences were observed in mean values between the reading times of the LA and HA sentence types in terms of FF durations. ( $\mathrm{p}=0,015)$. Significantly more time is spent reading the noun phrase that immediately comes after the RC area considering LA sentence type.

For TF duration reading times, descriptive statistics are presented in Table 4 below.

Table 4. Descriptive Statistics on Attachment Types for AoI 2 (NP1) in TF Duration

\begin{tabular}{lccc}
\hline Type of Attachment & Mean & Std. Deviation & N \\
Low Attachment &, 5529 &, 16692 & 60 \\
High Attachment &, 4497 &, 16880 & 60 \\
\hline
\end{tabular}

Considering the mean values, LA sentence type $(X=, 5529)$ has a higher mean value compared to the HA $(X=, 4497)$ sentence type. In order to see whether the differences in these mean values have a statistical significance, T-test was administered. The results from the test indicate that a significant difference between the groups is the case. 
In total processing time of this AoI, there is a significant ease for the HA sentences. It is assumed that the parser verifies the initial processing strategy while reading the given sentences with the HA. This could be attributed to the fact that the processing of NP1 as the only agent/theme of the action in RC (AoI1) area depending on whether it is a SRC or ORC sentence. This is a similar result to the one that is gathered from the RC (AoI1) area. The LA sentence type reading times for the specified area is significantly longer than that of the HA sentences. It could be stated that due to animacy-sensitiveness of the Turkish parser, an implicit local ambiguity is present in LA sentences. The parser is led down to the garden path trying to decide whether NP2 is the subject of RC preceding it or the direct object of the main verb. However, because of the same sensitiveness whether in early or late processing, HA sentences clear the ground for the parser to make right choices.

AoI3 is the second NP that follows the RC area. In LA sentences, it is the second NP that follows the RC area and it is also licensed as the agent/theme of the action in the RC. In HA sentences, the NP is a different word and serves as the direct object of the main verb. For LA sentences, a possessive marker is suffixed on the NP while the NP in HA sentences are inflected with an accusative marker. Despite the evident discrepancy in their function, NPs in both attachment types sound quite similar, which creates a context to analyze Turkish parser's behavior on processing in case of a potential ambiguity. Descriptive statistics for both sentence types are given below in Table 5 .

Table 5. Descriptive Statistics on Attachment Types for AoI 3 (NP2) in FF Duration

\begin{tabular}{llll}
\hline Type of Attachment & Mean & Std. Deviation & N \\
Low Attachment &, 2047 &, 03639 & 60 \\
High Attachment &, 2155 &, 05466 & 60 \\
\hline
\end{tabular}

For first fixation duration reading times of the aforementioned AoI, it seems that participants spent less time reading the area in LA $(X=, 2047)$ than HA $(X=, 2155)$. In order to see whether the differences in these mean values have a statistical significance, the T-test was administered; however, the results show that the significance value of ,068 between the LA and HA sentences indicate that this difference is not statistically significant $(p<0,05)$. This is the case considering the reading times of the early processing. In order to see the bigger 
picture in processing TF durations are presented in Table 6 below and further analysis is given.

Table 6. Descriptive Statistics on Attachment Types for AoI 3 (NP2) in TF Duration

\begin{tabular}{lcll}
\hline Type of Attachment & Mean & Std. Deviation & N \\
Low Attachment &, 5840 &, 22716 & 60 \\
High Attachment &, 6741 &, 27528 & 60 \\
\hline
\end{tabular}

As can be seen in Table 6, HA $(\mathrm{X}=, 6741)$ sentences include reading times that are higher than that of LA sentences $(X=, 5840)$. T-test results also support the result indicating that a significant mean value difference $(\mathrm{p}=0,001)$ exists between LA and HA sentences in terms of NP2 area.

In the initial analysis of the LA sentences, AoI3 is another possible agent/theme candidate for the action in RC. Thus, when reading is continuing, this area, without losing time, is added into the node opened for the previous NP (AoI2) which presents evidence for the Late Closure (Frazier and Fodor 1978). The semantic properties of NP2 also raise its chance to be included into the opened node. Hence, the initial processing of this area is relatively shorter than that of HA sentences as they include a different type of NP due to the semantic properties.

Table shows that the HA sentences are processed in unprecedentedly longer time. Considering the semantic/pragmatic properties of the HA sentences, it is safe to state that AoI3 is not a candidate for the agent/theme position of the action in the RC area. Unlike the incremental and smooth processing of the aforementioned AoIs, the parser's initial analysis of this area takes particularly longer than it does in other AoIs. It results from the fact that on this point, the parser selectively stops and perceives NP2 as the direct object of the main verb thus creating a separate node for it even during the initial processing of the given sentences. This realization and the related operations are carried out even in initial reading, which is considerable. It proves that the Turkish parser possesses syntactic parsing and semantic/pragmatic awareness at the same time.

The spillover area (AoI4) is worth considering as it provides insights into the cognitive load of the previous AoIs. AoI3 (NP2) is one of the central parts of the study, and analyzing the 
word next to it in terms of reading times (means, standard deviations) and seeking statistically significant differences possibly gives us better understanding into the parsing strategies.

As seen in the sentences above, the spillover words are the same among all sentences. They are also selected to be adverbs. The main motivation for choosing adverbs for this position is to help the parser stop adding more incoming materials into the attachment operation.

In Table 7 below, the descriptive statistics for the LA and HA sentence types are given.

Table 7. Descriptive Statistics on Attachment Types for AoI 4 (Spillover) in FF Duration

\begin{tabular}{lclc}
\hline Type of Attachment & Mean & Std. Deviation & N \\
Low Attachment &, 2114 &, 04213 & 60 \\
High Attachment &, 2031 &, 03652 & 60 \\
\hline
\end{tabular}

Table clearly indicates that the means for the sentence types have quite similar results considering the FF duration reading times. The higher reading time belongs to the LA sentence type $(X=, 2114)$ followed by HA $(X=, 2031)$.

In order to see whether the differences in these mean values have statistical significance, the T-test is administered. Table shows that there are significant differences only between the reading times of the LA and HA sentence types $(\mathrm{p}=, 021)$.

The TF duration reading times for spillover area (AoI 4) are presented in Table 8 below.

Table 8. Descriptive Statistics on Attachment Types for AoI 4 (Spillover) in TF Duration

\begin{tabular}{llll}
\hline Type of Attachment & Mean & Std. Deviation & N \\
Low Attachment &, 5784 &, 21438 & 60 \\
High Attachment &, 5721 &, 20425 & 60 \\
\hline
\end{tabular}

The lower reading times are observed at the HA sentences $(X=, 5721)$ closely followed by the LA sentences $(X=, 5784)$. T-test results also confirm that a statistical significance could not be observed between the LA and HA sentence types $(p=, 889)$.

Although certain significant differences were reached pertaining to reading times of the attachment types, for AoI4 such discrepancy to discuss on was not reached. It is, however, safe to state that in the context of the present study, a spillover effect was not observed.

Year 4/ 2020, Volume-4, Issue-3 | WWW.ispecjournal.org 
The last AoI that was investigated in the study is the main verb. It is one of the key elements that helped us observe the attachment processing load and preferences. Licensing of arguments assigned by the main verbs can be explained by scrutinizing reading times. As seen in the sentences above, all the main verbs consist of different actions. In addition, in order to satisfy the attachment type criteria, the verb in the LA sentence is a transitive verb. On the other hand, the verbs in the HA are ditransitive.

FF duration reading times for AoI5 are presented in Table 9 below.

Table 9. Descriptive Statistics on Attachment Types for AoI 5 (MV) in FF Duration

\begin{tabular}{llll}
\hline Type of Attachment & Mean & Std. Deviation & $\mathbf{N}$ \\
Low Attachment &, 1703 &, 03618 & 60 \\
High Attachment &, 1558 &, 04036 & 60 \\
\hline
\end{tabular}

Mean values of the participants on reading the main verbs of the sentence types indicate that LA sentences $(X=, 1703)$ required them to process this AoI with longer durations than HA sentences $(X=, 1558)$. $T$ - test results also support that concerning reading times of the area of interest, there are significant differences between the LA and HA sentence types $(p=, 005)$.

AoI 5 is also analyzed in terms of the TF duration reading times between the two attachment types. In Table 10 below, the descriptive statistics for two target sentence types are given.

Table 10. Descriptive Statistics on Attachment Types for AoI 5 (MV) in TF Duration

\begin{tabular}{lcll}
\hline Type of Attachment & Mean & Std. Deviation & N \\
Low Attachment &, 3051 &, 09788 & 60 \\
High Attachment &, 2673 &, 07763 & 60 \\
\hline
\end{tabular}

Table indicates that the LA sentences $(X=, 3051)$ include higher reading times than the HA sentences $(X=, 2643)$. Regarding the results of $T$-test, significant differences were observed among the groups as significance values are lower than $0,05(\mathrm{p}=, 001)$.

For the TF reading times, significant differences between the two sentence types were observed when compared to each other. Once again, HA sentences have the lower reading times $(X=, 2673)$ than LA sentences $(X=, 3051)$. Analysis for the FF reading times can also account for the TF reading times. According to Ferreira and Henderson $(1991,1998)$, the Year 4/ 2020, Volume-4, Issue-3 | WWW.ispecjournal.org 
main verb acts as an error signal. This is the location in a given sentence where the parser notices the ill-formed syntactic tree for the locally ambiguous sentence. Departing from this assumption, the parser feels the urge to check their syntactic analysis to confirm that they reach the intended meaning of the given LA sentences. Comparative ease on HA sentences concerning the analysis of the main verb AoI confirms the hypothesis that Turkish parser prioritizes HA.

\subsection{Analysis of Answers to Comprehension Questions}

Accompanying the findings from sentence type processing section, data from the answers to the comprehension questions are revealed, and it is discussed whether there is a correlation between the online processing preferences and offline comprehension questions. As a reminder, a pair of comprehension questions is provided below.

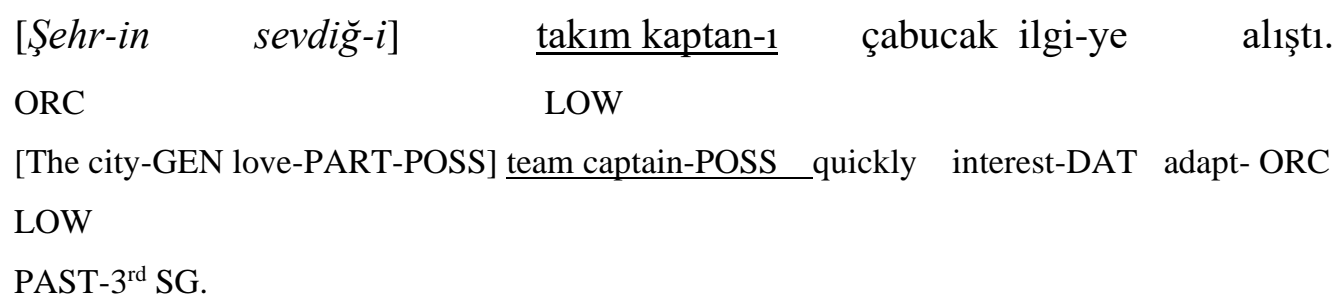

The team captain whom the city loves quickly adapted to attention. Comprehension Question

(19)

Takım çabucak ilgi-ye alış-tı. Yanlış

The team-NOM quickly interest-DAT adapt-PAST- $3^{\text {rd }}$ SG.

The team quickly adapted to attention.

False

The gathered data from the comprehension questions are divided into three groups based on the sentence types. The table below presents descriptive statistics and normality distribution. The Kurtosis Normality test indicated that the data obtained had a normal distribution as seen in Table 12. 
Table 12. Descriptive Statistics and Normality Distribution of Attachment Types for Correct Answers to Comprehension Questions

\begin{tabular}{lcccc}
\hline Type of Attachment & Mean & Std. Deviation & Kurtosis & Std. Error \\
& & & Statistic & \\
Low Attachment & 12,0333 & 4,18215 & 2,262 &, 608 \\
High Attachment & 12,9667 & 2,64233 & 7,090 &, 608 \\
\hline
\end{tabular}

Similar to reading time analysis, answers to comprehension questions after reading the LA seem to be lower $(X=12,0333)$ than the HA sentences $(X=12,9667)$. HA sentences possess significantly higher accuracy than LA $(\mathrm{p}=, 001)$ according to the results of the T-test.

In line with the findings gathered from reading time analysis through eye-tracking device, the HA sentences involve higher success rates. It implies that the parsing and licensing of this type of sentence cause lesser cognitive load in sentence processing.

Regarding syntactic and pragmatic constraints gathered from the online eye-tracking data and offline comprehension questions, it is safe to discuss that Turkish is a language that allows high attachment to RCs. In this preference, there seems to be a strong correlation between the online and offline data.

\section{Conclusions}

Before dealing with the answers to the research question "What are the processing differences between the High and Low Attachment to RCs in Turkish?", it can be stated that even in initial processing, the Turkish speakers were observed to present a high degree of lexical semantic awareness when it comes to adding new words into the phrase that is being processed along with utilizing syntactic information. When processing is considered in terms of reading times, a further conclusion to point out is that HA sentences take the parser shorter to process compared to the LA sentences, which is supported by Kırkic1 (2004) and 
Dinctopal-Deniz (2010). Overall, Turkish is suggested to be a HA language. In the HA sentences in the study, it was observed that a new node was created for NP2 (AoI3, namely the second NP that follows the RC) unlike the LA sentences, and this results in higher fixation times during the initial processing (first fixation duration) when the parser is exposed to the incoming flow of information. However, observed lower reading times in main verb (both in first and total fixation durations) is an indication that this online decision embracing both syntactic and more importantly semantic information is checked when reaching the main verb (lower fixation durations for the HA sentence type).

Another processing difference between the two attachment types is how central and crucial the role of the main verb is. It is indicated that the LA AoIs are comparatively processed slower than the HA AoIs. However, the difference is more significant in the observance of the main verbs. It is speculated that in processing of the LA sentences, the parser is not confident about the final parsing of a given sentence. The features and properties of the main verb are scrutinized extensively by the parser in order to reach the intended message of the sentence. The HA main verbs, on the other hand, significantly possess lower reading times. As it is indicated before, longer fixation durations on NP2 due to creating a new node is made so confidently that the main verb is not an area for confirmation anymore. To sum up, in the present study, the HA preference is supported as observed in the related studies by Kirkic1 (2004) and Dinctopal-Deniz (2010). Furthermore, due to the eye-tracker device used in the experiment, more fine-grained analyses were performed. For the LA sentences, the main verb is an indispensable part for confirming syntactic operations and attachment preferences; thus, decoding the intended meaning of a given sentence. For LA configuration, early processing is completed with relatively smoothly as the incoming materials do not interfere with the Late Closure (Frazier and Fodor 1978). On the other hand, for the HA sentences it is not the case. NP2 (Aol3) does not meet lexical semantic requirements of the action in RC and thus is not added into the node as the agent/patient even in early processing. Although this AoI requires relatively longer fixation duration, the parsing operation shortens the overall processing durations. Therefore, the parser does not rely on the argument structure of the main verb for checking. 


\subsection{Restrictions}

The study involves certain limitation to mention. -(y)An, -DIK are the only two RC markers for SRCs and ORCs respectively. Despite the fact that Turkish allows a number of other markers for relativization such as -(y)An, -DIK, -(y)AcAK (olan/olduK), -mIş (olan/olduK/olacaK) and ki, the two markers were included into the study to control the boundaries of the gathered data and it is due to the fact that $-(\mathrm{y}) \mathrm{An},-\mathrm{DIK}$ are major Turkish RC markers (Göksel and Kerslake, 2005).

\subsection{Acknowledgements}

The present study is the article form of my $\mathrm{PhD}$ dissertation at English Linguistics Department of Hacettepe University, Ankara/Turkey. With this opportunity, I would like to express my gratitude for Assoc. Prof. Dr. Emine Yarar for her guidance as a supervisor. For the implementation and analysis of the study, grants or scholarships were not used.

\section{References}

Abney, S.P. (1989). A computational model for human parsing. Journal of Psycholinguistic Research, 18: 129-144. https://doi.org/10.1007/BF01069051

Başer, Z (2018). Ana Dili Türkçe Olan Tek Dilli ve İngilizce Öğrenen Bireylerde İlgi Tümcelerinin Bağlanmasında Sözdizimsel Hazırlama. Unpublished PhD dissertation, Middle East Technical University.

Büyüköztürk, Ş. (2007). Sosyal Bilimler için Veri Analizi El Kitabı, Ankara: Pegem A Yayınc1lik.

Caplan, D., Vijayan, S., Kuperberg, G., West, C., Waters, G., Greve, D. and Dale, A., (2001). Vascular responses to syntactic processing : an event related fMRI study of relative clauses. Human. Brain Mapping. 15, (pp. 26-38).

https://doi.org/10.1002/hbm.1059

Crocker, M. (1996). Computational Psycholinguistics. Dordrecht: Kluwer Academic Publishers.

https://doi.org/10.1007/978-94-009-1600-5

Cuetos, F. and Mitchell, D. (1988). Cross-Linguistic Differences in Parsing: Restrictions on the Use of the Late Closure Strategy in Spanish. Cognition, 30: (pp. 73-105). 
https://doi.org/10.1016/0010-0277(88)90004-2

Dinçtopal-Deniz, N. (2010). Relative Clause Attachment Preferences of Turkish L2 Speakers of English: Shallow parsing in the L2. In B. VanPatten and J. Jegerski (Eds.), Research on Second Language Processing and Parsing (pp. 27-63). Amsterdam: John Benjamins. https://doi.org/10.1075/lald.53.02din

Eymen, U. E. (2007). SPSS Kullanma Kılavuzu. İstatistik Merkezi Yayın.

Ferreira, F. and Henderson, J. M. (1991). Recovery from misanalyses of garden-path sentences. Journal of Memory and Language, 25, (pp. 725-745).

https://doi.org/10.1016/0749-596X(91)90034-H

Ferreira, F. and Henderson, J. M. (1998). Syntactic reanalysis, thematic processing, and sentence comprehension. In J. D. Fodor and F. Ferreira (Eds.), Reanalysis in sentence processing (pp. 73-100). Dordrecht: Kluwer.

https://doi.org/10.1007/978-94-015-9070-9_3

Frazier, L. \& Fodor, J. D. (1978). The sausage machine: A new two-stage parsing model. Cognition. 6, 1-34.

https://doi.org/10.1016/0010-0277(78)90002-1

Frazier, L. (1978). On Comprehending Sentences: Syntactic Parsing Strategies. Unpublished Doctoral Dissertation, University of Connecticut, Storrs.

Frazier, L. (1979). On Comprehending Sentences: Syntactic Parsing Strategies. PhD dissertation, University of Connecticut. West Bend, IN: Indiana University Linguistics Club.

Frazier, L. (1987). Theories of Sentence Processing. In J. Garfield (ed.), Modularity in Knowledge Representation and Natural Language Understanding (pp. 291-307). Cambridge, MA: MIT Press.

Frazier, L. and Rayner, K. (1982). Making and correcting errors during sentence comprehension: eye movements in the analysis of structurally ambiguous sentences.

Cognitive Psychology, 14 (pp. 178-269). https://doi.org/10.1016/0010-0285(82)90008-1

Frazier, L. and Rayner, K. (1982). Making and correcting errors during sentence comprehension: eye movements in the analysis of structurally ambiguous sentences. Cognitive Psychology, 14 (pp. 178-269). https://doi.org/10.1016/0010-0285(82)90008-1

Frazier, L., and Clifton, C., Jr. (1996). Construal. Cambridge, MA: MIT Press.

George, D., and Mallery, M. (2010). SPSS for Windows Step by Step: A Simple Guide and Year 4/ 2020, Volume-4, Issue-3 | WWW.ispecjournal.org 
Reference, 7.0 update (10a ed.) Boston: Pearson.

Gibson, E., Hickok, G., and Schutze, C. T. (1994). Processing Empty Categories: A Parallel Approach. Journal of Psycholinguistic Research, 23, (pp. 381-405).

https://doi.org/10.1007/BF02143946

Gordon, P. C., Hendrick, R., and Johnson, M. (2001). Memory Interference During Language Processing. Journal of Experimental Psychology: Learning, Memory and Cognition, 27, (pp. 1411-1423).

https://doi.org/10.1037/0278-7393.27.6.1411

Hemforth, B., Konieczny, L., Scheepers, C. and Strube, G. (1998). Syntactic Ambiguity

Resolution in German. In D. Hillert (ed.), Sentence Processing: A Crosslinguistic

Perspective. Syntax and Semantics, vol. 31 (pp. 292-312). San Diego, CA: Academic Press. https://doi.org/10.1163/9780585492230_017

Kahraman, B (2015). Processing Turkish Relative Clauses in Context. In D. Zeyrek, Ç.S. Şimşek and U. Atas (eds.)

https://doi.org/10.2307/j.ctvc770nr.14

Kaya, M. (2010). Working Memory and Relative Clause Attachment Preferences in Turkish: An Eye-Tracking Study. Paper presented at International Conference on Turkish Linguistics 2010, Budapest, Hungary.

Kennedy, A. and Murray, W. (1984). Inspection times for words in syntactically ambiguous sentences under three presentation conditions. Journal of Experimental Psychology: Human Perception and Performance, 10, (p. 833-847).

https://doi.org/10.1037/0096-1523.10.6.833

King, J., and Just, M. A. (1991). Individual differences in syntactic parsing : The role of working memory. Journal of Memory and Language, 30, (p. 580-602).

https://doi.org/10.1016/0749-596X(91)90027-H

King, J., and Kutas, M. (1995). Who did what and when? Using word- and cause-level ERPs to monitor working memory usage in reading. Journal of Cognitive Neuroscience, 7, (p. 376$395)$.

https://doi.org/10.1162/jocn.1995.7.3.376

Kirkici, B. (2004). The processing of relative clause attachment ambiguities in Turkish. 12th International Conference on Turkish Linguistics. Dokuz Eylül University, Izmir.

Kornfilt, J. (1997). Turkish. London and New York: Routledge.

Kornfilt, J. (2000). Some Syntactic and Morphological Properties of Relative Clauses in Turkish; in The Syntax of Relative Clauses; A. Alexiadou, C. Wilder, and P. Law (eds.); 
Amsterdam/Philadelphia: John Benjamins, (p. 121-159).

https://doi.org/10.1075/la.32.04kor

Kornfilt, J. (2009). Turkish and the Turkic Languages. In B. Comrie (Ed.), The World's Major Languages (2. Edition). (pp. 519-544). London and NY: Routledge.

MacDonald, M.C. (1993). The Interaction of Lexical and Syntactic Ambiguity. Journal of Memory and Language, 32, (p. 692-715).

https://doi.org/10.1006/jmla.1993.1035

MacDonald, M.C. (1994). Probabilistic constraints and syntactic ambiguity resolution. Language and Cognitive Processes, 9, (pp. 195-201).

https://doi.org/10.1080/01690969408402115

MacDonald, M.C. (1997). Lexical Representations and Sentence Processing : An Introduction. Language and Cognitive processes, 12(2/3), (pp. 121-136).

https://doi.org/10.1080/016909697386826

MacDonald, M.C., Pearlmutter, N. and Seidenberg, M.S. (1994). The Lexical Nature of Syntactic Ambiguity Resolution. Psychological review, 101, (pp. 676-703).

https://doi.org/10.1037/0033-295X.101.4.676

MacWhinney, B. (1987). The Competition Model. In B. MacWhinney (Ed.), Mechanisms of language acquisition (pp. 249-308). Hillsdale, NJ: Lawrence Erlbaum.

MacWhinney, B. and Bates, E. (eds.) 1989. The Crosslinguistic Study of Sentence Processing . Cambridge: CUP.

MacWhinney, B. and Bates, E. (eds.) 1989. The Crosslinguistic Study of Sentence Processing . Cambridge: CUP.

Mazuka, R. \& Lust, B. (1990). On parameter setting and parsing: Predictions for crosslinguistic differences in adult and child processing. In L. Frazier \& J. de Villiers (Eds.), Language processing and language acquisition. (pp. 163-206). Dordrecht: Kluwer. https://doi.org/10.1007/978-94-011-3808-6_7

Mitchell, D.C. (1987). Lexical Guidance in Human Parsing: Locus and Processing Characteristics. In M. Coltheart (ed.), Attention and Performance XII: The Psychology of Reading (pp. 601-618). Hillsdale, NJ: Erlbaum.

Öztürk, B. T. and Erguvanlı E. (2016) Possessive Constructions in Turkish. Lingua. 182, (pp. 88-108).

https://doi.org/10.1016/j.lingua.2015.08.008

Papadopoulou, D. (2006). Cross-Linguistic Variation in Sentence Processing volume 36 of Year 4/ 2020, Volume-4, Issue-3 | WWW.ispecjournal.org 
Studies in Theoretical Psycholinguistics. Springer. https://doi.org/10.1007/1-4020-4690-1

Philips, C. (1996). Order and Structure. Unpublished PhD Dissertation, MIT.

Pickering, M. J. (1994). Processing Local and Unbounded Dependencies: A Unified Account. Journal of Psycholinguistic Research, 23, (pp. 323-352).

https://doi.org/10.1007/BF02145045

Pickering, M. J., Clifton, C. Jr., and Crocker, M. W. (2000). Architectures and Mechanisms in Sentence Comprehension. https://doi.org/10.1017/CBO9780511527210.002

Roland, D., Mauner, G., O'Meara, C. and Yun, H. (2012). Discourse Expectations and Schuman, H. and Presser, S. (1981). Questions and Answers in Attitude Surveys. New York: Academic Press.

Schuman, H., \& Presser, S. (1981). Questions and answers in attitude surveys: Experiments on question form, wording, and context. New York: Academic Press.

Spivey-Knowlton, M. and Tanenhaus, M.K. (1994). Referential Context and Syntactic Ambiguity Resolution. In C. Clifton, L. Frazier, and K. Rayner (eds.), Perspectives on Sentence Processing (pp. 415-439). Hillsdale, NJ: Erlbaum.

Spivey-Knowlton, M., and Sedivy, J. C. (1995). Resolving Attachment Ambiguities with Multiple Constraints. Cognition, 55, (pp. 227-267).

https://doi.org/10.1016/0010-0277(94)00647-4

Tabachnick, B.G., Fidell, L.S. (2013). Using Multivariate Statistics (sixth ed.) Pearson, Boston.

Tanenhaus, M. K., Spivey-Knowlton, M. J., Eberhard, K. M., and Sedivy, J. C. (1995). Integration of visual and linguistic information in spoken language comprehension. Science, 268, (pp. 1632-1634).

https://doi.org/10.1126/science. 7777863

Taraban, R. and McClelland, J.L. (1990). Parsing and Comprehension. In D. Balota, G.B. Flores D' Arcais, K. Rayner, Comprehension Processes in Reading (pp. 231-263). Hillsdale, NJ: Lawrence Erlbaum.

Thornton, R., Gil, M. and MacDonald, M. (1998). Accounting for Cross-Linguistic Variation: A Constraint-Based Perspective. In D. Hillert (ed.), Sentence Processing: A Crosslinguistic perspective. Syntax and Semantics, vol. 31 (pp. 211-223). San Diego, CA: Academic Press. https://doi.org/10.1163/9780585492230_013 
Thornton, R., MacDonald, M. and Gil, M. (1999). Pragmatic Constraints on the Interpretation of Complex Noun Phrases in Spanish and English. Journal of Experimental Psychology:

Learning, Memory, and Cognition, 25(6): (pp. 1347-1365).

https://doi.org/10.1037/0278-7393.25.6.1347

Traxler, M. (2012). Introduction to Psycholinguistics: Understanding Language Science. Chichester, West Sussex: Wiley-Blackwell.

Traxler, M. J., Morris, R. K., and Seely, R. E. (2002). Processing Subject and Object Relative Clauses: Evidence from Eye Movements. Journal of Memory and Language, 47, (pp. 69-70). https://doi.org/10.1006/jmla.2001.2836

Traxler, M., Williams, R. S., Blozis, S. A., and Morris, R. K. (2005). Working Memory, Animacy, and Verb Class in the Processing of Relative Clauses. Journal of Memory and Language, 53, (pp. 204-224).

https://doi.org/10.1016/j.jml.2005.02.010

Trueswell, J., Tanenhaus, M. K., and Kello, C. (1993). Verb-Specific Constraints in Sentence Processing: Separating Effects of Lexical Preference from Garden-Paths. Journal of Experimental Psychology: Learning, Memory, and Cognition, 19, (pp. 528-553). https://doi.org/10.1037/0278-7393.19.3.528

Turan, C. (2012). Degree of Access to Universal Grammar/Transfers from L1 in the Learning of Relative Clauses by Turkish Learners of English. Unpublished master's Thesis, Hacettpe University.

Underhill, R. (1974). Turkish participles. Linguistic Inquiry, 3, (pp.87-99).

Waters, G. S., and Caplan, D. (1992). The Capacity Theory of Sentence Comprehension: Critique of Just and Carpenter. Psychological Review, 103, (pp. 761-772). https://doi.org/10.1037/0033-295X.103.4.761

Weckerly, J., and Kutas, M. (1999). An Electrophysiological Analysis of Animacy Effects in the Processing of Object Relative Sentences. Psychophysiology, 36(5), (pp. 559-570). https://doi.org/10.1111/1469-8986.3650559

Weinberg, A. (2001). A Minimalist Theory of Human Sentence Processing. In S.P. Epstein, N. Hornstein (eds.), Working Minimalism. Cambridge, MA: MIT Press.

White, L. (2003). Second language acquisition and universal grammar. Cambridge University Press: Cambridge, UK. https://doi.org/10.1017/CBO9780511815065 